\title{
CRÍTICA Y ¿DEFENSA? DE LAS MUJERES EN UN «SERMÓN» SATÍRICO NOVOHISPANO PROHIBIDO POR LA INQUISICIÓN (1795) ${ }^{1}$
}

\author{
María IsABel TERÁn Elizondo \\ Universidad Autónoma de Zacatecas - México \\ isabelteran@uaz.edu.mx \\ SONIA IBARRA VALDEZ \\ Universidad Autónoma de Zacatecas - México \\ sonia_ibarra_9@hotmail.com
}

$\square$

119 de julio de 1795, don Baltasar Ladrón de Guevara, por entonces regente de la Audiencia de México, dirigió al inquisidor Juan de Mier y Villar la denuncia de un papel satírico manuscrito y anónimo que, según declara, le ofreció un conocido suyo para que se divirtiera. Sin embargo, en lugar de gracioso, el denunciante consideró el escrito «insufrible», por «desatinado y maldito», por lo que le detalla a su destinatario las razones por las que debería recogerse y prohibirse.

Sus quejas abarcan varios aspectos. Por un lado, critica la intención explícita del desconocido autor de persuadir al lector de que las mujeres «son, por su malicia, peores y más nocivas que los demonios»; por otro, el que para probar dicho aserto recurriera a estrategias reprobables por estar comprendidas en varias prohibiciones, como el hacer uso de lo sagrado con fines profanos, al titular la sátira como Sermón, al tratar a Eva, la madre de la humanidad, «como una indigna

\footnotetext{
$1 \quad$ Este artículo se ha desarrollado dentro del proyecto «La mujer frente a la Inquisición española y novohispana» (FEM2016-78192-P), I+D de Excelencia del Ministerio de Economía y Competitividad (MINECO), financiado por la Agencia Estatal de Investigación (AEI) y el Fondo Europeo de Desarrollo Regional (FEDER, UE); y del grupo de investigación «Mentalidades mágicas y discursos antisupersticiosos (siglos XVI, XVII y XVIII)», grupo consolidado por la Universidad Autónoma de Madrid.
}

Edad de Oro, XXXVIII (2019), pp. 293-314, ISSN: 0212-0429 - ISSNe: 2605-3314

DOI http://doi.org/10.15366/edadoro2019.38.016 
fregona», y al abusar de las Sagradas Escrituras sacando pasajes de su significación y contexto original.

También denuncia que el escrito contenga proposiciones «bárbaras, temera[rias], escandalosas y mal sonantes», y extiende sus opiniones negativas incluso hasta el aspecto literario, al juzgar «que el verso carece de alma y [graci]a, sin arte ni concierto». El querellante temía que anduvieran «esparcidas muchas copias» del texto, provocando perjuicios espirituales en los lectores, dado el gusto de la gente por «la mordacidad y la maledicencia» (1795: f. 2r).

Su acusación motivó la apertura de un expediente inquisitorial que felizmente se encuentra completo (AGN, Inq., 1.372, exp. 16, ff. 1r-35v). La controversia se resolvió en poco tiempo, ya que el último documento está datado el 25 de noviembre del mismo año. La secuencia de las acciones fue la siguiente: la denuncia (fechada el 19 de julio, recibida en la Inquisición el 21), la orden de remisión del papel a calificación (6 de agosto), la primera censura (24 de agosto, recibida en la Inquisición el 26), el requerimiento de una nueva calificación (31 de agosto), la segunda censura ( $₫$ ? de octubre, recibida en la Inquisición el 7), la resolución del inquisidor fiscal de que se prohibiera el papel y se indagara sobre la existencia de otros ejemplares para que se recogieran (9 de octubre), y el mandato de que la prohibición del papel se notificara en el siguiente edicto y la exhortación al denunciante de que manifestara el nombre de quien se lo entregó (13 de octubre). Del 20 de octubre al 25 de noviembre, los inquisidores recabaron las declaraciones de quienes habían tenido en su poder el Sermón, tras lo cual dieron por concluido el proceso.

Reconstruyendo la historia relatada en las declaraciones de los involucrados, podría decirse que las cosas fueron así: alrededor de 1790, es decir, cinco años antes de la denuncia, el librero Francisco González (ya fallecido para las fechas del proceso) le prestó a José Antonio Troncoso², escribano real público de la Diputación y Fiel Ejecutoria, un ejemplar del Sermón para que hiciera una copia. En su alegato, Troncoso conjetura que González podía haberlo adquirido en alguna venta de bienes, pues era valuador de libros.

Sin que explique por qué, el escribano conservó durante varios años y sin ningún escrúpulo tanto el original de González como la copia que le hizo, ya que aseguró que dos frailes dominicos, fray Vicente Velasco y el padre Pensado, lo leyeron sin que le encontraran objeción. Hacia 1794 Troncoso reconoce que le entregó la copia a Juan Aguilar ${ }^{3}$, oficial impresor en la imprenta de Jáuregui, con el fin

2 En el proceso se da una confusión de identidad: se cita por error a declarar a don Jerónimo José Troncoso, hijo de José Antonio Troncoso, del mismo apellido y ocupación.

3 El nombre de este personaje varía en la transcripción de las declaraciones. Aparece como Juan Aguilar, Juan José Aguilar y Juan Antonio Aguilar. Probablemente sea un error del escribano. 
de que este lo memorizara para recitarlo en eventos sociales como divertimiento, como al parecer solía hacerlo con otros textos similares.

El otro manuscrito quedó en su poder hasta que por alguna razón, tampoco aclarada, lo dejó en casa de las hermanas Escamilla, que se lo prestaron a Francisco Villegas, oficial platero, que a su vez se lo pasó a Tomás Morquecho, administrador del estanco de pieles, quien fue el que se lo ofreció al regente Baltasar Ladrón de Guevara. Al final del proceso Juan Aguilar entregó también su ejemplar al Santo Oficio, y como nadie admitió conocer el nombre del autor ni saber de la existencia de más copias, el asunto se dio por concluido.

Ahora bien, lo interesante de este Sermón no es tanto su discurso misógino, ni la estrategia de la sátira, así como tampoco el hecho de que pasara de mano en mano durante muchos años, circunstancias todas presentes en otros escritos prohibidos novohispanos de la misma centuria, como han constatado varios autores (Miranda y González Casanova 1953; González Casanova [1958] 1986; Baudot y Méndez 1997; Méndez [1996] 2001: 135-149), sino el hecho de que en la denuncia, el regente de la audiencia de México cuestionara que el anónimo autor equiparara a las mujeres con los demonios, cuando este sexo era calificado por la Iglesia como «devoto». Bajo este supuesto, cabría esperar que en los argumentos de las censuras en los que se fundamentó la prohibición del papel, se haría una defensa del género femenino.

El objetivo de este ensayo consiste, por tanto, en determinar si el discurso de la Iglesia, representado por la opinión de los calificadores e inquisidores, propuso argumentos en defensa de las mujeres y, en su caso, cuáles y de qué tipo y en qué fuentes se basaron.

\section{Los MANUSCRItos Del SERMóN Y QUÉ SE HA DICHO HASTA AHORA DE ELLOS}

Como ya se dijo, el expediente inquisitorial resguarda dos ejemplares del extenso poema satírico mal llamado Sermón: uno encuadernado y mejor conservado, de 13 folios numerados (inserto entre los ff. 10v-11r) al que en adelante se hará referencia como ms. 1; y otro escrito a dos columnas, sin numerar y en desorden (hh. 11r-15r) o ms. 2. En este último caso, la reconstrucción del texto se pudo lograr a partir de la rima y del cotejo con el otro cuadernillo.

Al analizar ambos documentos, resulta evidente que, en contradicción con lo declarado por Troncoso, ninguno es una copia del otro. Aunque en el fondo dicen lo mismo, la secuencia del discurso es muy diferente y su extensión es distinta. El ms. 1 tiene 616 versos, mientras que el ms. 2 solo 487; pero, lo más significativo, es que este último incluye citas latinas tomadas principalmente de la Biblia, mientras que el primero las omite, o las traduce o parafrasea en español. 
Si asumimos que el «original» fuera el ms. 1 que, según las declaraciones de Troncoso, González podría haber adquirido en una subasta de bienes (lo cual tendría sentido porque es el cuadernillo empastado y podría venderse como un libro), el ms. 2 sería el duplicado; pero, si la petición explícita del librero fue que el escribano elaborara una "copia», ¿por qué este alteraría el texto modelo cambiando el orden de varios pasajes, eliminando otros y añadiendo citas latinas y una copla popular? ${ }^{4}$ Nada sugiere en sus declaraciones que no siguió las instrucciones de González.

La mayor extensión de uno de los manuscritos y su discurso en español podrían explicarse a partir de su probable éxito entre los lectores u oyentes, que bien podrían haber esperado del copista o del recitador la traducción de las citas latinas, e incluso que se le añadieran nuevos pasajes o coplas populares para alargar y diversificar la diversión ${ }^{5}$; sin embargo, Troncoso tampoco da indicios de que pudo haber dado a conocer el texto entre más personas de las que menciona. En cambio, si supusiéramos que el «original» es el ms. 2, sería más fácil creer que en la copia el escribano «tradujera» los pasajes latinos, pero no hay modo de explicar que agrandara el «original» añadiéndole más de cien versos, ni que hubiera invertido dinero en empastarlo.

Es por esta razón por la que en este ensayo se propone que, pese a lo declarado por Troncoso, se trata de dos versiones distintas de un mismo texto y que, la más breve, precisamente por la inclusión de los pasajes latinos, sería la más cercana a un hipotético texto base hasta ahora desconocido, incluso probablemente anterior y quizá ni siquiera novohispano. Esta hipótesis no resuelve sin embargo el enigma, pues quedan muchos asuntos sin resolver: ¿quién mintió respecto a los manuscritos y por qué?, ¿de dónde salió la segunda versión?, ¿por qué el escribano no hizo lo que le encomendaron?, ¿por qué le dio a Juan Aguilar la supuesta copia y conservó el «original»? Lamentablemente no hay manera de resolver estas cuestiones con la información proporcionada por el expediente.

Hasta donde fue posible indagar, solo dos investigadoras han dado a conocer este Sermón y una de ellas lo ha estudiado desde un punto de vista similar, pero no idéntico, al que aquí se propone. La primera fue Anastasia Krutytskaya (2008: 5-50) quien lo presenta de forma breve reseñando el proceso inquisitorial y su relación con el discurso misógino, para enseguida transcribir las dos versiones con

4 «Si la mar fuera de tinta,/ y el cielo todo papel,/ y los peces escribanos,/ cada uno con siete monos,/ no escribirán en cien años/ la maldad de una mujer» (ms. 2, vv. 478-480). De esta copla hubo muchas versiones (Frenk 1975-1985: n. ${ }^{\circ} 250$ ). Hoy, incluso, se puede encontrar completa o versos sueltos en poemas y canciones, como se puede constatar con una búsqueda en Internet.

5 Un caso similar es el de las coplas anónimas del Chuchumbé, cuyo éxito propició que los lectores o intérpretes le fueran agregando más coplas en el proceso de recepción y circulación. Véase Bailes y sones deshonestos en la Nueva España (1998). 
algunas notas de edición y erudición. Para Krutitskaya, el ms. 2 es solo una «copia parcial y desordenada» del otro, pero no da explicaciones del porqué de las diferencias.

La segunda fue Estela Castillo Hernández (2014: 33-62) quien al parecer no conoció el estudio anterior, pues no lo cita en su artículo, por lo que incluye un apéndice con su propia transcripción del ms. 1, también con notas de edición y erudición, aunque su versión discrepa en algunos puntos de la de Krutitskaya ${ }^{6}$. Para Castillo, el manuscrito «incompleto» es también solo «una copia alterada» del otro ejemplar, aunque ella sí arriesga una hipótesis del porqué de sus diferencias. Por ejemplo, opina que las citas bíblicas, parafraseadas en español en el ms. 1, se cambiaron en el ms. 2 al latín «con la intención de acentuar en la obra el tono de prédica religiosa». La investigadora asume además que Troncoso introdujo en la copia esos cambios con el objetivo de acercar el texto al público (2014: 36), aunque como ya se dijo, el escribano no dice nada sobre este punto.

A favor de su hipótesis estaría el que, efectivamente, un texto más breve sería más fácil de memorizar para un recitador; sin embargo, es difícil sostener el supuesto de que el público prefiriera que el texto contuviera frases latinas que traducidas o parafraseadas en español, por lo que aquí se sostiene la hipótesis de que los manuscritos son en realidad dos versiones de un tercero que podría ser el original.

En cuanto a su estudio, aunque Castillo cataloga el Sermón como un ovillejo con rima consonante y da cuenta de las vicisitudes del proceso (2014: 33-35), tomando como base para su análisis el ms. 1 , se enfoca principalmente en exponer tres aspectos de la obra:

1. La comparación del Sermón con un texto anterior, con título y tema semejante, escrito en 1735 por el preso Joseph Gómez del Valle (2014: 36-37), dado a conocer por María Águeda Méndez (2001: 135-149).

2. La estrategia de la parodia de un verdadero sermón.

3. El discurso misógino (2014: 37-43). Estos dos últimos temas son analizados en un solo apartado como cuestiones entrelazadas.

Con el análisis que aquí se propone se espera complementar estos dos estudios previos.

6 En otro espacio comentaremos nuestras coincidencias y diferencias con ambas transcripciones, así como sobre la interpretación o anotación de algunos vocablos. 


\section{El Discurso MisóGino y LAS ESTRATEGias DE LA SÁtiRA}

Como ya se dijo, el Sermón fue escrito con la burlesca intención de demostrar que la supuesta maldad de las mujeres excede a la de los demonios y, como consecuencia de ello, persuadir a los hombres de que evitaran tener trato con ellas si querían tener una vida tranquila y salvar su alma.

Coincidimos con las dos investigadoras mencionadas en que el satírico estaba al tanto de los tópicos del discurso misógino difundido desde la antigüedad por autores como Semónides, Aristófanes, Teofrasto, Lucilio, Ovidio y Juvenal, entre otros; y perpetuado en la Edad Media por la tradición cristiana, teniendo como fuente principal el Génesis, donde se considera inferior a Eva y subordinada a Adán por haber sido creada en segundo lugar y a partir de una parte suya, pero, sobre todo, por ser la culpable del pecado original y de su trasmisión a toda la humanidad, debido a que su debilidad la llevó a sucumbir ante las tentaciones del demonio, arrastrando en su caída a su pareja; aunque muchos otros pasajes bíblicos del Antiguo Testamento (Proverbios, Eclesiástico, Eclesiastés) y algunos del Nuevo (principalmente en las epístolas de san Pablo), lo reiteran (Archer 2001: 21; Puig Rodríguez-Escalona 1995: 11-12).

Debido al conocimiento directo o indirecto de estas fuentes o de las tradiciones que originaron, presentes de manera implícita o explícita en el Sermón, podría decirse que su autor fue una persona culta, probablemente un religioso, a pesar de que el texto circuló entre un grupo de personas de diverso estrato social e intelectual que tenían en común el saber leer; aunque de haberlo memorizado y recitado Juan Aguilar, como era su propósito, quizá hubiera llegado a un público iletrado.

Antes de entrar al análisis del discurso misógino del Sermón es preciso recordar algunos elementos de la tradición literaria de la que forma parte, para constatar sus deudas con ella.

Varios autores reconocen que, de la literatura antigua, es en la sátira VI de Juvenal donde se concentran muchos de los tópicos del discurso misógino posterior. En ella el poeta latino intenta disuadir a su destinatario, Póstumo, de contraer matrimonio, mostrándole un desalentador panorama del género femenino, pues en su opinión no hay mujer buena, y todas tienen defectos y vicios, como poca vergüenza y ser derrochadoras, orgullosas, vanidosas, dominantes, supersticiosas, coquetas, intrigosas, lujuriosas, celosas, tercas, indóciles y discutidoras (Sátiras 1817: 135-136). Además de tener predisposición al vicio y a los excesos, y ser soberbias, adúlteras, infieles, desleales, engañadoras, desenfrenadas, habladoras, impúdicas, volubles, crueles y hasta hechiceras o criminales (Cortés Tovar 2000, 30-33).

A partir de la antología de diversas fuentes, Mercè Puig Rodríguez-Escalona (1995) y Robert Archer (2001) reseñan la historia de este discurso misógino en la 
Edad Media, y coinciden en identificar algunas categorías, el primero en la poesía latina, y el otro en textos españoles, aunque, por lo menos el segundo admite que varios de los defectos o vicios que desde la perspectiva actual son considerados negativos, eran entonces parte del conocimiento del dominio común y se les atribuían a las mujeres sin que se entendieran como agravios (Archer 2001: 20).

Ambos autores coinciden además en que la razón de que los textos contra las mujeres incrementaran entre los siglos XI y XIII fue la reforma de la vida religiosa, a partir de la cual se invitaba a los hombres a retirarse del mundo para llevar una vida de contemplación en conventos y monasterios (Puig Rodríguez-Escalante 1995: 12-14; Archer 2001: 31). Por tanto, las mujeres, vistas como la «personificación de la lujuria», fueron consideradas como una amenaza contra la castidad, «la fuente de todos los males» y las culpables de la corrupción de las virtudes masculinas (Puig Rodríguez-Escalante 1995: 14 y 19).

En los textos que recopila, Archer identifica que a partir de las ideas de Aristóteles la mujer es percibida como un género accesorio o un hombre mutilado o imperfecto (2001: 23). Noción corporal que se trasladó a lo moral. Y el mejor ejemplo era Eva, que encarnó todos los males que heredó a su género (2001: 26). Solo María estaba exenta al haber sido escogida por Dios para ser la madre de Cristo (Puig Rodríguez-Escalona 1995: 23). Es así que el ideal femenino medieval consistía en que las mujeres imitaran a esta en la virginidad, o en que adoptaran virtudes masculinas, ya que no se reconocía ninguna propia del género (Archer 2001: 27).

Los autores mencionados coinciden también en distinguir dos tipos de discursos misóginos: el que buscaba la salvación del alma de las mujeres haciendo patentes sus vicios para ser enmendados y, en el contexto de las obras de amor cortés, el de vituperio, fruto del despecho por el rechazo de una dama (Archer 2001: 43-44; Puig Rodríguez-Escalante 1995: 14-15), aunque Puig Rodríguez-Escalante confiesa que «no siempre es fácil distinguir con nitidez» las intenciones de los autores (1995: 15).

Retomando elementos de distintos textos, Archer enumera algunos de los defectos o vicios que se les atribuían a las mujeres y que son muy similares a los propuestos en la sátira VI de Juvenal: falta de control en el hablar, inconstancia para llevar a cabo sus propósitos, poco seso, proclive a los excesos y peligrosa (2001: 18-19). Además se les acusa de glotonas, lujuriosas, perezosas (2001: 1920), frágiles, necias, inconstantes, soberbias, irascibles (2001: 31), malagradecidas, perezosas, infieles, traicioneras, alcahuetas, astutas (2001: 38-39), mentirosas y no merecedoras de amor, porque esta pasión era nociva y enfermaba al hombre privándolo de razón (2001: 41).

Puig Rodríguez-Escalante hace su propio listado a partir de sus fuentes: volubilidad, inconstancia (ligera de palabra, mentirosa y perjura), engañosa, infiel 
(adúltera), venal (avariciosa y codiciosa) y cruel (1995: 14-15). Y agrega un párrafo en el que sintetiza la esencia de ese discurso misógino:

[...] la mujer es principalmente la gran responsable de los males del mundo, provoca el desorden, la destrucción y la ruina por doquier, es ella la que incita el mal e incita a él, dado que es malvada y criminal y se halla afectada por impulsos irresistibles que toman como modelo todas las deshonras y prohibiciones. Se la retrata asesina, furibunda, impía, inconciliable, ladrona, litigosa, maledicente, necia, soberbia, vengadora y con un inmenso poder para alcanzar sus propósitos. Su maldad es tal que los poetas misóginos recurren al topos retórico de lo indecible, a saber, la apelación a la imposibilidad de contarlo todo sobre las maldades femeninas (1995: 19).

Este mismo autor identifica además algunos tópicos de esta literatura:

1. La mujer igualada con la serpiente como símbolos de lujuria.

2. La mujer vista como enemigo del hombre y aliada de Satanás (1995: 20).

3. Recuento de los «sabios caídos» a causa de las mujeres: Adán, Sansón, David y Salomón (1995: 22).

4. Molestiae nuptiarum: los horrores que padecen los hombres imprudentes que cometen el error de casarse (1995: 24).

Finalmente, Archer señala que en muchas obras la exageración grotesca de los defectos y vicios enlistados daba pie a la comicidad, recurso retórico que facilitaba alcanzar el propósito didáctico de prevenir a los hombres de que huyeran de las mujeres (2001: 33-35).

Como bien lo señalaron Krutitskaya y Castillo Hernández, el Sermón novohispano encaja perfectamente en la tradición descrita. Y ya Castillo estableció los paralelismos paródicos entre él y una verdadera pieza retórica (2014: 39-46), por lo que aquí basta con decir que podrían identificarse en ambos manuscritos algunos apartados claves, aunque el poema esté escrito de corrido: un preámbulo burlesco y de doble sentido donde se compara el intento de población de Roma por parte de Rómulo $^{7}$ con el objetivo del texto: caer sobre las mujeres. El relato de la creación del mundo para justificar la maldad del género femenino: el hombre y el mundo se perdieron por ellas. Argumentos y pruebas de que las mujeres son peores que

7 Se refiere al relato del rapto de las sabinas por parte de los romanos para poblar Roma durante unas fiestas organizadas por Rómulo para tal fin, a las que invitaron a sus vecinos, el pueblo sabino. La enemistad entre ambos linajes se dilató muchos años hasta que durante un enfrentamiento, las mujeres sabinas los hicieron entrar en razón convenciéndolos de que hicieran las paces, porque ambos pueblos tenían mucho que perder con la muerte de los contendientes, pues estaban emparentados. 
los demonios: catálogo de maldades y vicios. Y conclusión y recomendación: para salvarse hay que huir de ellas.

Bajo estos supuestos, el Sermón mantiene en todo momento la oposición maniquea hombres ingenuos y buenos/mujeres malvadas que los inducen al pecado y a la perdición ${ }^{8}$.

Para sustentar sus proposiciones, el satírico recurre a pasajes de autores profanos, religiosos y bíblicos, pese a que las citas son vagas, por lo que en algunos casos es difícil identificar el original. Los autores que se mencionan son: san Agustín, san Jerónimo, san Pablo, san Buenaventura, san Juan, san Pedro, san Tirso, Juan Guarín, Orígenes, Catón, Eurípides y Estrabón; y los textos: el Apocalipsis, el Génesis y Job. En todos los casos los pasajes citados o parafraseados son sacados de su contexto o parodiados para servir a los fines burlescos del discurso.

La premisa que sustenta esta diatriba es que la mujer es culpable de haber caído en los engaños del demonio y, con su falta, «maleó a Adán» (ms. 1 v. 89; ms. 2 , v. 67) y condenó a toda la humanidad.

Es la mujer la misma execración, madre del delito y la confusión.

Sois mujer la primera transgresora y de la Ley Antigua violadora

(ms. 1, vv. 417-420). hizo más estrago que centella, pues, de malear a su marido, todito el universo está perdido: el mundo, digo, tan tierno y flamante, quedó dado al demonio en un instante

(ms. 1, vv. 88-92).

Los defectos o vicios que se le atribuyen en el texto - astuta, vanidosa, insumisa, rebelde, antojadiza, libertina, arrojada, caprichosa, terca, de corto entendimiento, chismosa, entrometida, odiosa, engreída, murmuradora, amante de fiestas y convites, falsa letrada, afilada de lengua, terrible, feroz, contumaz, inflexiblecoinciden con los del discurso misógino medieval, e incluso parten del supuesto de la sátira VI de Juvenal de que no hay mujer buena.

no la puede sufrir su vanidad;

si se les da permiso en sus antojos

obran con libertad dos mil arrojos;

si un hombre no les quita la ocasión,
Pues no se os pasa día sin indagar

cómo pasa el vecino en el lugar,

lo que pasa en la plaza

y en lo más escondido de una casa.
Otro cualquier vicio pudiera ser lo letrado, por cierto, en las mujeres, pero mal que ocasiona el desconcierto

de su maldita lengua, no, por cierto,

$8 \quad$ Para el análisis del texto citaremos nuestra propia transcripción de ambos manuscritos. Tomaremos como base el ms. 1 y aludiremos al ms. 2 sin mencionar las variantes, pues no son asunto de este estudio. 
a cada paso pierden la razón En fin, con la mujer no vale nada,

no hay medio ni razón que la persuada,

pues ni su entendimiento les importa

ni el ajeno [il.] las reporta

(ms. 1, vv. 277-287;

ms. 2, vv. 317-322).
¿Cómo come fulana?, ¿cómo viste?

¿quién es el miserable que la asiste?

¿el que vive, el que pierde y el que gana?

¿quién entra en casa de zutana?

Tragándose un lugar desde un estrado

no como quien se come un pavo asado, que al fin quedan ilesos

$\mathrm{y}$ con poco de carne algunos huesos

sino que todo lo devoran todo

(ms. 1, vv. 451-460;

ms. 2, vv. 350-352). pues no deja este mal, el más tirano,

una parte sola, ni un hueso sano.

Esto os hace, mujeres, ser odiosas,

$\mathrm{y}$ nace de que sois muy codiciosas,

y de ahí viene que sean murmuradoras, y de lo bueno fieras tragadoras

(ms. 1, vv. 467-476).

Trasladando algunos de estos defectos o vicios a un contexto cristiano, podría decirse que se asume que las mujeres son propensas a cometer todos los pecados capitales.

En consonancia con la tradición misógina en la que se inserta, en el Sermón se asume que la maldad, la vileza y lo despreciable son parte de la naturaleza femenina:

Nada, sino la antigua inclinación que tenéis a lo malo, a la vileza, porque en vosotras es naturaleza, conservando mejor lo despreciable que el consejo más santo y saludable

(ms. 1, vv. 98-602; ms. 2, vv. 466-471).

Los adjetivos que se les adjudican a las mujeres también se orientan en la tradición descrita, muy en el estilo de los enumerados por Puig Rodríguez-Escalante. Aquí se les llama malditas, malditas hembras, hembras sucias, duendes caseros, diablos domésticos caseros, falsas sirenas, escoria indecible, de lo bueno fiera tragadora, detestables, execrables, arma formidable, bestia infernal, madre del delito y la confusión, primera transgresora, bestia fiera y formidable, lenguas del demonio, «golondrinas malditas chilladoras. / Filomenas parleras / avecillas crueles y vocingleras» (ms. 1, vv. 494-496).

Y para el autor del Sermón, el mundo es un desastre por la sola existencia de las mujeres: 
¡Qué cierto es que este mundo es mundo inmundo, desde que hubo mujeres en el mundo! Ya en él no se ven si no es obscuridades, desdichas, hambre, guerra, enfermedades, muertes, robos, males, apostasías, gentilismo, judaísmo y herejías

(ms. 1, vv. 204-209; ms. 2, vv. 122-127).

Para completar el panorama, el texto reproduce los tópicos identificados por Puig Rodríguez-Escalante: animalizándola, la mujer es comparada con el escorpión por el daño que causa con su veneno, con las hormigas por su cantidad (ms. 1, v. 265), con el jumento por su falta de seso (ms. 1, v. 594), con las míticas sirenas por su seducción (ms. 1, v. 267), y con la serpiente, la culebra, el áspid, el basilisco y la esfinge por su asimilación al demonio y su simbolismo de la lujuria:

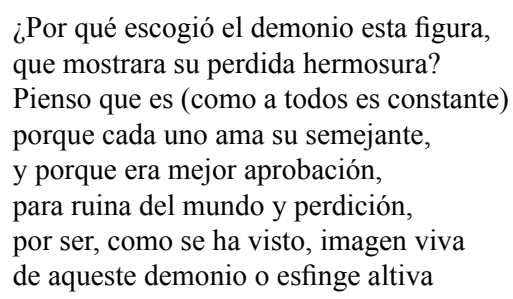

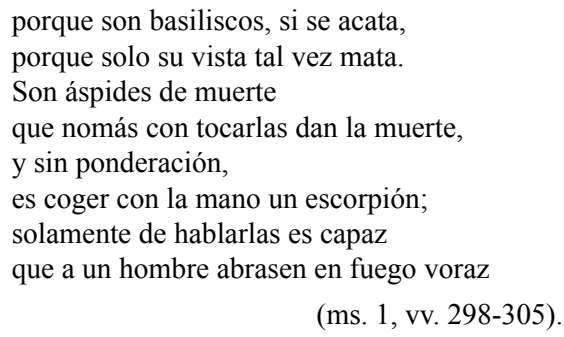

(ms. 1, vv. 298-305).

De hecho, el Sermón lleva más allá la semejanza entre la mujer y la serpiente al equipararlas en el plano físico: comen tierra, andan a la moda, se desplazan bamboleándose, son venenosas, mudan de piel, cuando «meten» la cabeza en algo no hay quien pueda sacárselas (ms. 1, vv. 507-558) y tienen la vida y la honra en la cola (ms. 2, vv. 424-434).

El segundo tópico consiste en presentar a la mujer como enemiga del hombre y aliada de Satanás. Para este discurso misógino, el hombre es una inocente víctima de las maquinaciones femeninas, cuyo fin es perderlo - aunque nunca se aclara la razón de este encono ni de este propósito - por lo que mantiene una perpetua guerra con él:

\footnotetext{
¡Ay, pobrecitos hombres, miserables! ¿Que enemigos tenéis tan formidables! [...]

Siempre nos condenáis a eternos llantos, nos apartáis de Dios y de sus santos.
} 
Todos vuestros desvelos

son cerrarnos las puertas de los cielos, abrasar a todo hombre el pensamiento, destruir la voluntad y entendimiento; robarles todo el bien y la virtud, quitarles el dinero y la salud con una rabia atroz, sin dejar que se vuelvan a su Dios, pues le robáis el alma y la razón llenarles de tiniebla el corazón (ms. 1, vv. 180-181, 188-199; ms. 2, vv. 224-225, 234-241).

En cuanto a la alianza de la mujer con Satanás y sus demonios, el autor lleva esta parte del tópico a otro nivel, ya que la considera más poderosa, malvada, dañina y peligrosa que ellos, pues despliegan mañas y astucias que les son ajenas:

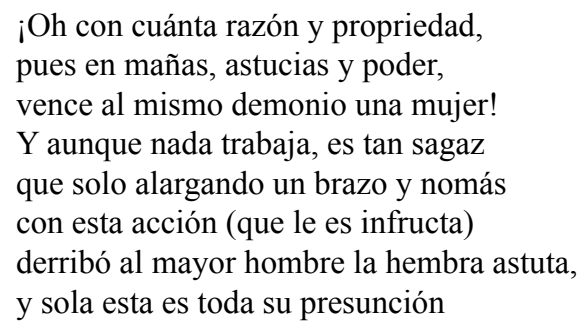

¡Oh con cuánta razón y propriedad, pues en mañas, astucias y poder, vence al mismo demonio una mujer! $\mathrm{Y}$ aunque nada trabaja, es tan sagaz que solo alargando un brazo y nomás con esta acción (que le es infructa) derribó al mayor hombre la hembra astuta, y sola esta es toda su presunción

(ms. 1, vv. 133-140; ms. 2, vv. 76-79).

Es así que mientras el ángel caído arrastró al infierno solo a las milicias rebeladas, la mujer condenó a «todo el universo»; en tanto que los demonios tientan a muchos pero pierden a pocos, esta perdió a todos, «los que han de nacer, los que ya nacieron / ningunos se escaparon» (ms. 1, vv. 117-130). A los demonios se les enfrenta y hay manera de rendirlos mediante conjuros, cruces o agua bendita, pero a las mujeres no hay forma de vencerlas, pues «no hay virtud, fortaleza ni poder, / aunque uno se sepulte en una sierra, / o se meta debajo de la tierra» (ms. 2, vv. 176-178; ms. 1, vv. 172-173).

Este tópico está íntimamente ligado al de los sabios caídos, hombres cuyas virtudes no les sirvieron de mucho para defenderse de las argucias femeninas, como la sabiduría de Salomón, la fuerza de Sansón, la santidad de David, o la bravura de los israelitas (ms. 1, vv. 335-346; ms. 2, vv. 185-196). El autor completa este catálogo canónico con los ejemplos del gran estratega militar Julio César, cautivado y sometido por Cleopatra (ms. 1, vv. 347-350; ms. 2, 
vv. 197-200), de España perdida debido a la pasión de Rodrigo por Florinda ${ }^{9}$ (ms. 1, vv. 397-400; ms. 2, v. 206) y de la crisis inglesa por la locura de Enrique VIII «perdido por una hembra de Iberia» ${ }^{10}$ (ms. 1, vv. 401-404; ms. 2, vv. 207-210). En relación con esto el autor del Sermón recuerda el consejo de Job: «que una mujer [...] es suficiente / de hacer apostatar al más sapiente» (ms. 1, vv. 395-396) ${ }^{11}$.

Por último, podría decirse que aunque no de manera explícita, aparece también el tópico del molestiae nuptiarum, cuando se recomienda que las mujeres no merecen ser amadas:

¿Y que haya hombres, señores, tan atroces, que se mueran por bestias tan feroces?

Siendo ellas de por sí tan detestables, tan malditas, tan sucias y execrables. Vuelvo a decir, mujeres engreídas, no podéis ser queridas en ninguna manera, ni aun siquiera dejar que un hombre os quiera.

Oíd a san Agustín lo que de vosotras dice a este fin:

No solo le es prohibido a una mujer que a ningún hombre pretenda querer, pero lo que es más, están prohibidas hasta de aquel deseo de ser queridas porque por tales, teneros debéis, que aun el hombre más ruin no merecéis

(ms. 1, vv. 571-586; ms. 2, vv. 447-456).

Ante todo este panorama, la recomendación del autor es huir de las mujeres.

San Pedro dice en su carta primera que no huyamos el cuerpo nunca afuera,
Para agradar a Dios, es menester huir (pues lo dice así) de la mujer:

$9 \quad$ Leyenda española medieval sobre la caída del imperio visigodo de Toledo. Florinda, hija del conde don Julián de Septem (Ceuta), es enviada a la corte de don Rodrigo, último rey visigodo. Él se enamora de ella pero ante su rechazo la secuestra y la fuerza. El padre de Florinda la venga aliándose con los musulmanes, quienes en el 711 lo vencieron en la batalla de Guadalete, iniciando la ocupación árabe de la península ibérica.

10 Castillo asume que se trata de Ana Bolena, pero tendría que referirse a Catalina de Aragón (2014: 42).

11 «Su mujer le dijo: “ ¿Todavía vas a mantenerte firme en tu integridad? Maldice a Dios y muere de una vez"» (Job 2: 9). 
y con grande eficacia nos intima

a la lid con el diablo y nos anima

a que le hagamos cara

con valor y fortaleza rara ${ }^{\mathbf{1 2}}$;

y el mismo apóstol, en la crecida guerra, que no[s] hace la mujer en la tierra, temiendo sus alardes,

«Huye, huye» ${ }^{\mathbf{1 3}}$, nos dice y no la aguardes, ¿con que al Diablo aguardarlo cara a cara y a las mujeres huirlas? ¡Cosa rara!

(ms. 1, vv. 142-153; ms. 2, vv. 166-173). huir de ellas, no mirarlas,

nunca oírlas ni tocarlas

(ms. 1, vv. 294-297; ms. 2, vv. 261-262).

Aunque el satírico es consciente de la dificultad de llevar esto a la práctica, ya que los hombres tienen que convivir con ellas en la propia casa y «en la calle, en la iglesia y en la plaza», teniendo «por compañeros / a estos diablos domésticos caseros» (ms. 1, vv. 235-238).

En cuanto a los recursos satíricos, ya se dijo que en cierta forma el texto es la parodia de un sermón. Sin embargo, quizá el recurso más recurrente es la degradación o reducción. J. C. Hodgart define así esta estrategia: «la degradación o desvalorización de la víctima mediante el rebajamiento de su estatura y dignidad. Esto puede conseguirse en el terreno del argumento y casi siempre se proseguirá en el del estilo y el lenguaje» (1969: 115). Ejemplo de ello son el «empequeñecimiento», como hace Swift con los liliputienses en Los viajes de Gulliver; el «desnudamiento», que le sustrae a la víctima sus apoyos de rango y clase social, como en la narración de El traje nuevo del emperador; la «animalización», que reduce las acciones humanas al mero instinto animal; «la locura o la irracionalidad» que lo despoja de la libertad y la cordura; la «tipificación» que le arrebata su individualidad; y la «caricatura», que resalta uno de sus defectos físicos o morales, etc. (1969: 108-133).

Como podrá constatarse, en todos los sentidos, la mujer es «desnudada» y degradada en el Sermón al ser reducida a sus instintos, defectos, vicios, pecados y a su supuesta semejanza física o moral con algunos animales, todos ellos considerados nocivos. Esto, aunado a la exageración y la hipérbole, y a la obscenidad y los juegos de palabras, brindan al lector una caricatura ridícula del género femenino, de la que se excluye solo a la Virgen María.

12 «Sean sobrios y estén siempre alerta, porque su enemigo, el demonio, ronda como un león rugiente, buscando a quién devorar. / Resístanlo firmes en la fe, sabiendo que sus hermanos dispersos por el mundo padecen los mismos sufrimientos que ustedes» (Primera Carta de san Pedro 5: 8-9).

13 El autor confunde a san Pedro con san Pablo. No encontramos una cita exacta de los pasajes que le atribuye a este. 
Esta degradación se lleva también a otros extremos. En el terreno textual, por ejemplo, al parodiar otros tipos discursivos, como el sermón o formas poéticas, haciendo que sirvan para el vituperio en lugar del que la poética o la retórica les otorga. Otra estrategia consiste en tomar pasajes históricos, literarios o míticos, como el del rapto de las sabinas, otorgándole otro sentido para equipararlo con lo que se busca expresar, pero con un sentido obsceno:

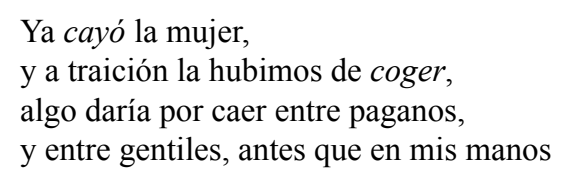

(ms. 1, vv. 81-84; ms 2, vv. 59-62).

Un recurso más serían las paráfrasis de las citas de textos sagrados y profanos, al ser extrapolados de su contexto y significado original para convertirlos en «pruebas» de un discurso muy diferente e incluso contrario a lo que realmente dicen. Tal es el caso del cambio de sentido de varios pasajes del Antiguo Testamento, como este del Génesis, torcido para mostrar la maldad de las mujeres:

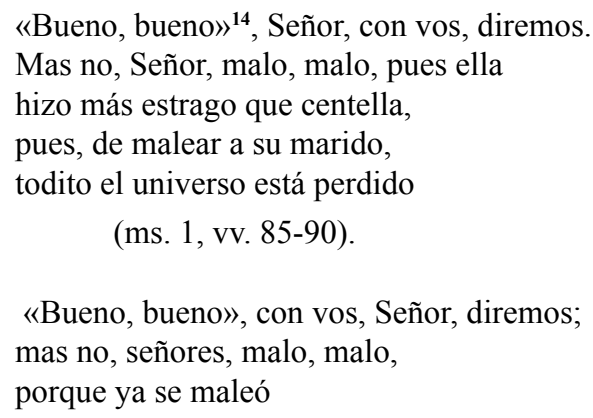

(ms. 2, vv. 64-66).

Por todo lo expuesto podría decirse que el Sermón novohispano no presenta ninguna innovación o desviación de la tradición medieval del discurso misógino.

\section{La ¿DEFENSA? DE LAS MUJERES POR LOS CALIFICADORES}

Paralela a la tradición del discurso misógino, Archer expone la existencia de otra dirigida a la defensa de las mujeres, cuya fuente principal también es la Biblia.

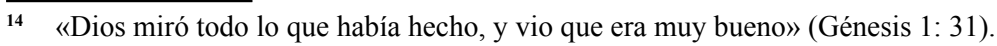


Y uno de los primeros ejemplos es De mulieribus claris, de Boccaccio, «publicado en castellano en 1494» (2001: 46). Dichos textos eran una respuesta a los vituperios de los despechados amantes «maledicentes», entre ellos el propio Boccaccio, y se trataba de listas de mujeres «virtuosas y valientes», «con alguna breve alusión a sus hazañas o virtudes», generalmente «del Antiguo Testamento, del mundo clásico y de la edad cristiana» (2001: 51).

Sin embargo, como ya se había señalado, el modelo de perfección femenina que prevalece en estas obras se restringe a dos posibilidades: el permanecer virgen, ya que se pensaba que tal condición evitaba muchos de los defectos atribuidos al género; y/o el asemejarse al varón, como aquellas mártires o santas que lograron anular su feminidad sacrificado partes de su cuerpo o sobreponiéndose a sus instintos naturales como el de la maternidad (2001: 52). Es así que la supuesta defensa de las mujeres en esos textos y posteriores, consistía esencialmente en señalar las excepciones del género, por lo que resulta iluso pensar que los censores novohispanos siguieron una vía diferente, lo cual deslindamos a continuación.

Los calificadores asignados para censurar el sermón fueron los franciscanos fray José Francisco Valdés y fray Juan Guadalupe de León, religiosos descalzos del convento de San Diego de México, quienes respondieron con rapidez al encargo. Ambos coincidieron en recomendar que el papel debería ser recogido y prohibido, aunque el segundo propone además que fuera quemado. Los dos son así mismo muy sistemáticos en su exposición de motivos, pues los dividen en varios puntos. A continuación se analizan en conjunto sus argumentos, dejando para el final los relacionados con la defensa de las mujeres.

La mayor preocupación de los calificadores residía en que el papel abusaba de las Sagradas Escrituras y «las letras de los Santos Padres» (1795: f. 5r); esto es, que sacaba de su contexto pasajes considerados parte del discurso de la Revelación o hablan de lo sagrado, con el fin de aplicarlos a un asunto profano: criticar a las mujeres, dándoles «una inteligencia forzada y violenta, y hacie[ndolas] decir lo que no dice[n]»; pero además dispuestos de tal modo que se pretendía imitar el «tono de un orador evangélico» para desarrollar un asunto burlesco. Ambos censores coinciden en señalar que esto era una transgresión codificada en las normas inquisitoriales de la época que citan: el Manuale qualificatorum sanctae Inquisitionis... de Alberghini de 1754 y el Expurgatorio del Índice de libros prohibidos... de 1789.

El ejemplo que los dos calificadores eligen para mostrar este delito es el del pasaje bíblico del Génesis «Et vidit Deus quod set bonum» que el Sermón parafrasea tergiversando su sentido original, haciendo que Dios «apruebe» el malicioso sentido propuesto por la sátira, y que reniegue de la bondad de la creación de la mujer. Fray Juan Guadalupe de León califica este atrevimiento de blasfemia herética y señala una más: la osadía del autor de invocar a la Virgen María como apoyo 
para llevar a buen fin su execrable intento. Tan detestable consideran los censores este abuso que fray José Francisco Valdés recuerda varios ejemplos — tomados del mismo libro de Albergini- de poetas que recibieron un castigo divino por su atrevimiento.

Íntimamente relacionado con la queja de que el Sermón profana los textos sagrados, es que también abuse «del estilo de la Iglesia, intitulando "sermón" a su pieza ridícula, y vistiéndola de algunas circunstancias con que trata de imitar aquel estilo sagrado con que la santa Iglesia acostumbra o elogiar a sus santos o instruir a sus fieles» (1795: f. 3r-v); es decir, se objeta que el texto sea la parodia de un verdadero sermón.

Excediéndose en su función — que tocaba al contenido de la obra—, ambos calificadores se aventuran a opinar sobre el aspecto literario del Sermón en cuanto al uso de recursos como la hipérbole, la sátira, los juegos de palabras obscenos y la mala rima de los versos, al grado de que fray José Francisco Valdés recomienda que se prohíba también el papel por «por insulto gra[ve] y atrevido que comete el desacato de graznar entre los cisnes del Par[naso]».

Por último, fray Juan Guadalupe de León señala dos circunstancias importantes del Sermón no mencionados por el otro calificador, que ya de por sí daban a entender la perversidad del papel y lo ubicaban como candidato a ser prohibido: el hecho de ser manuscrito y además anónimo. En sus censuras, ambos censores van aplicándole al Sermón varios calificativos acordes con los conceptos expuestos en las fuentes legales en las que sustentan sus dictámenes: blasfemo, malsonante, escandaloso, injurioso, temerario, impío, desvergonzado, ofensivo a oídos piadosos y herético.

Ahora bien, en cuanto a la defensa de las mujeres, los calificadores convienen en reconocer que el único objetivo del anónimo autor es denostarlas cargándolas «de oprobios y maldiciones» y haciéndolas «reas de todo lo malo que hay en el mundo» por lo que se trata de una obra injuriosa, y por tanto quedaba comprendida en las prohibiciones inquisitoriales. Ambos concuerdan también en que el satírico establece doctrinas falsas, como la vieja premisa de la sátira VI de Juvenal de que no hay mujer buena, generalizando lo que quizá podría aplicarse a unas cuantas; aunque el autor del Sermón sí deja abierta la posibilidad de excluir a alguna mujer, quizá pensando en la Virgen María: «que son las mujeres, no es absoluta, / peores que los demonios, sin disputa» (ms. 1, vv. 99-100).

La «defensa» de los censores consiste, no en demostrar que las mujeres son buenas, como cabría esperar, sino solamente en argumentar que no todas son malas. La primera demostración, que repite lo expresado por Baltasar Ladrón de Guevara en su denuncia, consiste en señalar que la aseveración del satírico carece de razón y autoridad porque la Iglesia llama «devoto» al sexo femenino. Es decir, es la única virtud que se le reconoce como género. 
Sin sustentar la parte de este primer argumento que habla de que el supuesto del satírico carece de razón, fray José Francisco Valdés pasa a reflexionar sobre la parte de la autoridad, comentando que aun cuando el reconocimiento de la Iglesia hacia las mujeres como «sexo devoto» se aplicara en la letra solo a las religiosas, los papas habían canonizado santas, por lo que se debía suponer que Roma autoriza la idea de que hay algunas mujeres buenas. Fray Juan Guadalupe de León recurre al mismo argumento de autoridad: ha habido mujeres santas y el trato con ellas pudo haber resultado en provecho de los hombres, aunque admite que es cierto que se tenía prohibido a los eclesiásticos el trato con mujeres, pero no con todas, sino solo con aquellas de las que se «sospechara maldad».

Por otro lado, fray Juan Guadalupe de León reconoce también que así como se pueden esgrimir ejemplos de mujeres por las que se han perdido reinos y hombres, también las hay que han favorecido lo contrario, y asegura que eso consta en historias católicas, unas aprobadas por Roma y otras «fidedignas». Un argumento de autoridad más a favor de que existen algunas mujeres buenas lo encuentra fray José Francisco Valdés en santa Teresa de Jesús, a quien cita en un pasaje de su Vida... $(40,8)$, donde la religiosa afirma que había muchas más mujeres que hombres a los que Dios les hacía la merced de aprovechar el camino de la religión.

No encontrando quizá más argumentos teológicos o literarios, fray José Francisco Valdés recurre a una estrategia distinta: atacar al autor acusándolo de infame, porque critica a las mujeres pero nació de una; injusto, porque las condena por culpas atribuibles a los hombres, refiriéndose a la lujuria; e ingrato porque solo por pertenecer a este género la madre de Dios, merece ser venerado.

\section{ReFLEXIONES FINALES}

Lo dicho hasta aquí permite realizar varias reflexiones. La primera, que los calificadores argumentan en sus censuras exactamente lo mismo que expresó Baltasar Ladrón de Guevara en su denuncia. ¿Coincidencia o formulismo del propio trabajo de calificación? No hay modo de saberlo.

Lo segundo, que a pesar de que para 1795 en la Nueva España circulaban ya muchas lecturas e ideas ilustradas, ni el Sermón ni los calificadores se hacen eco de ellas. Por ejemplo, llama la atención que el poema satírico no haga mención de algunos vicios «ilustrados» en las mujeres novohispanas de finales del virreinato, como el cortejo, la marcialidad, las modas, el paseo, las comedias, las tertulias o el afrancesamiento, que sí se criticaron en otras obras satíricas contemporáneas, como Elementos del cortejo (s.f.), Tratado breve y compendioso del cortejo y la marcialidad (s.f.) y Cartilla de la moderna para vivir a la moda (1762), todos ellos antologados por Miranda y González Casanova (1953), o en la novela $L a$ 
Quijotita y su prima (1819) de José Joaquín Fernández de Lizardi. Esto apoya la idea de que quizá el Sermón aquí analizado sea de una época anterior y quizá ni siquiera novohispano, pues no contiene alusiones localistas que permitan ubicarlo en el virreinato de Nueva España.

Por otro lado y como es evidente, la defensa de los calificadores se apega al modelo medieval reseñado, donde el ideal femenino se identifica con vírgenes (las religiosas) y mártires «varonizadas» (las santas), mientras que el resto de las mujeres parecen caer inevitablemente en la categoría de «malas», pues en ningún momento los censores ponen en duda ni la existencia ni el origen de esa maldad, ni cuestionan o rebaten ninguno de los pecados, vicios y defectos que se le imputan al género, sino que se limitan a refutar la generalización de que todas sean iguales.

Sin embargo, en el fondo de este discurso misógino parecen advertirse dos cosas: por un lado, la paradoja de que, al denostar y ubicar a la mujer en un nivel más bajo que el de los demonios, en realidad la sitúa por encima de las capacidades humanas y demoniacas, admitiendo que tiene un poder natural y sobrenatural ajeno a hombres y demonios; y por otro, el miedo derivado de la toma de conciencia de que ese poder - o la suficiente astucia e inteligencia - es suficiente para controlar al hombre y/o conseguir siempre lo que ella desea.

Por último, vale la pena advertir que podría considerarse al Sermón como una forma tardía de un vituperio - aunque no precisamente escrito por el despecho de un mal de amores-, pues aunque incluye el tópico retórico de persuadir a los hombres de huir de las mujeres, esto no es lo que la sátira espera de sus lectores o escuchas, como tampoco lo es la corrección moral de las mujeres, pues es solo un innegable divertimiento a costa de ellas, no en balde circuló de mano en mano solo entre hombres.

\section{BiBLIOGRAFÍA}

ArCHER, Robert (2001). Misoginia y defensa de las mujeres. Antología de textos medievales. Madrid/Valencia: Cátedra/Universidad de Valencia $<$ https://books.google. com.mx/books?id=fUFyDFsaT3AC\&printsec $=$ frontcover\&dq=Misoginia $+y+$ defensa + de + las + mujeres $\&$ hl $=$ es-419\&sa $=$ X\&ved $=0$ ahUKEwj2kYfQz-7hAhVE M6wKHVhRDb0Q6AEIKDAA\#v=onepage \&q $=$ Misoginia $\% 20 \mathrm{y} \% 20$ defensa $\% 20$ de\%20las\%20mujeres\&f=false $>$ [Consulta: 20/04/2019].

Archivo General de la Nación (AGN - México), Inq., 1.372, exp. 16, ff. 1r-35v. Expediente formado en virtud de denuncia hecha por el Sor. Rexente don Baltasar Ladrón de Guevara sobre un cuadernillo manuscrito.

Bailes y sones deshonestos en la Nueva España (1998). Veracruz: Instituto Veracruzano de Cultura. 
BAudot, George y María Águeda MÉndez (1997). Amores prohibidos. La palabra condenada en el México de los virreyes. Antología de coplas y versos censurados por la Inquisición de México. Ciudad de México: Siglo XXI.

Beltrán Noguer, M. Teresa y Angela SÁnchez-La Fuente Andrés (2008). «La sátira sexta de Juvenal o el tópico de la misoginia». Myertia, 23, pp. 225-243<https://revistas. um.es/myrtia/article/view/71271/68601> [Consulta: 15/04/2019].

Cortés Tovar, Rosario (2001). «Misoginia y literatura: la tradición grecorromana». En María Teresa López de la Veja (ed.), Feminismo. Del pasado al presente. Salamanca: Universidad de Salamanca, pp. 15-34 <https://books. google.com.mx/books?id=VbwK6vfai4oC\&pg=PA16\&dq=La+sátira+sexta+ $\mathrm{de}+$ Juvenal\&hl=es-419\&sa $=$ X\&ved $=0$ ahUKEwiEwfT8vO7hAhWSvZ4KHce ND7EQ6AEIPTAE\#v=onepage \&q=La\%20sátira\%20sexta\%20de\%20Juvenal\& $\mathrm{f}=$ false $>$ [Consulta: $15 / 04 / 2019]$.

«Elogio del Señor Don Baltasar Ladron de Guevara, Regente que fué de esta Real Audiencia, y Consejero honorario en el Supremo de las Indias». Ciudad de México: Diario de México, sábado 16 de mayo de 1807, VI, n. ${ }^{\circ}$ 594, pp, 60-63<https://books. google.com.mx/books?id=fM6bqUdFBJkC\&pg=PA61\&dq=\%22Baltasar+Ladron + de + Guevara, + regente $\% 22 \&$ hl=es-419\&sa=X\&ved=0ahUKEwiCuID-98DhAh UPOK0KHYuJB5QQ6AEIKDAA\# $\mathrm{v}=$ onepage $\& \mathrm{q}=\% 22$ Baltasar $\% 20$ Ladron $\% 20$ de\%20Guevara\%2C\%20regente\%22\&f=false $>$ [Consulta: 15/04/2019].

FRENK, Margit (coord.) (1975-1987). Cancionero folcklórico de México. Ciudad de México: El Colegio de México.

GonzÁlez Casanova, Pablo [1958] (1986). La literatura perseguida en la crisis de la colonia. Ciudad de México: CONACULTA.

Hodgart, J. C. (1969). La sátira. Madrid: Guadarrama.

Índice último de los libros prohibidos y mandados expurgar: para todos los reynos y señoríos del católico rey de las Españas, El Señor Don Carlos IV (Año de M. DCCXC.). Madrid: Imprenta de don Antonio de Sancha.

JIMÉNEZ DE BÁEZ, Ivette (1969). Lírica cortesana y lírica popular actual. Ciudad de México: El Colegio de México.

Juvenal (1817). Sátiras: traducidas en verso por el Ilustrísimo Monseñor Licenciado Don Luis Folgueras Sion, Camarero intimo de S.S., Ablegado Apostólico, Dean de la Santa Iglesia de Orense, y Académico correspondiente de las Reales Academias de la Historia, y Latina Matritense. Con las licencias necesarias. Madrid: Imprenta de doña Catalina Piñuel <https://books.google. com.mx/books?id=taIU1 TYcwR8C\&pg=PA268\&dq=Sátira+IV+Juvenal\&hl $=$ es-419\&sa $=$ X\&ved=0ahUKEwjB88zGt-7hAhWQTd8KHeCIDJsQ6AEINTAC $\# \mathrm{v}=$ onepage\&q=Sátira\%20IV\%20Juvenal\&f=false $>$ [Consulta: 15/04/2019].

Krutitskaya, Anastasia (2008). «En contra de las mujeres: dos versiones de un sermón (México, 1795)». Revista de Literaturas Populares, VIII, n. ${ }^{\circ} 1$, pp. 5-50<http:// www.rlp.culturaspopulares.org/textcit.php?textdisplay $=416 \&$ batchdisplay $=>$ [Consulta: 15/04/2019]. 
Manuale qualificatorum sanctae Inquisitionis, inquo, Omnia quae ad illud Tribunal ac Haeresum censuram pertinent, brevi methodo adducuntur; Episcopis, Inquisitoribus, eorum Ministris, Theologis, Consultoribus, Confessariis, \& Jurisconsultis perutile \& necessarium. Autore R.P. F. Joanne Alberghini Panormitano, Terti Ordinis Sancti Francisci Regularis Observantiae S.T. Doctore ac S. Officii Regni Siciliae Qualificatore,. Cum duplici Indice, uno Capitum, altero rerum \& verborum copiosissimo. Editio Prima Veneta, quam emendatissime. Venetiis: Dominico Deregni, in via Mercatoria sub Signo D. Antonii (1754). Superiorum permissu, ac privilegio <https://books.google.com. $\mathrm{mx} /$ books? $\mathrm{id}=\mathrm{sSBLXAK} 3 \mathrm{tA} 4 \mathrm{C} \& \mathrm{pg}=\mathrm{PA} 59 \& \mathrm{dq}=$ Son + licet + cum + Deo, + aut + sanctis, + aut + rebus + divinis + jocari\&hl $=$ es $-419 \&$ sa $=X \& v e d=0$ ahUKEwjzhIWB mIXhAhXKzIMKHVCJDTkQ6AEIKjAA\#v=onepage \&q=Son $\% 201$ icet $\% 20$ cum $\% 20$ Deo $\% 2 \mathrm{C} \% 20$ aut $\% 20$ sanctis $\% 2 \mathrm{C} \% 20$ aut $\% 20$ rebus $\% 20$ divinis $\% 20$ jocari $\& \mathrm{f}=$ false $>$ [Consulta: 07/04/2019].

MÉNDEZ, María Águeda [1996] (2001). «La suerte de un pliego suelto en la Inquisición novohispana». Secretos del oficio. Avatares de la Inquisición novohispana. Ciudad de México: Universidad Nacional Autónoma de México, pp. 135-149.

Miranda, José y Pablo González Casanova (1953). Sátira anónima en el siglo XVIII. Ciudad de México: Fondo de Cultura Económica.

Puig Rodríguez-Escalona, Mercé (1995). Poesía misógina en la Edad Media latina (ss. XI-XIII). Barcelona: Universidad de Barcelona <https://books.google.com. $\mathrm{mx} /$ books? $\mathrm{id}=\mathrm{UPIMMGph} 92 \mathrm{IC} \&$ printsec $=$ frontcover $\& \mathrm{dq}=$ Poes $\% \mathrm{C} 3 \% \mathrm{AD}$ a + misógina + en + la + edad + media + latina\&hl $=$ es $-419 \&$ sa $=X \& v e d=0 a h U K E w$ iO-uG84e 7hAhVMLKwKHXSdCMgQ6AEIKDAA\#v=onepage\&q=Poes \%C3\%ADa\%20misógina $\% 20$ en $\% 201 \mathrm{a} \% 20$ edad $\% 20$ media $\% 201$ atina\&f=false $>$ [Consulta: 20/04/2019].

Souviron LóPEZ, Begoña (2010). «El ejemplo en el discurso misógino de la narrativa medieval». En Investigaciones multidisciplinares en género II Congreso Universitario Nacional Investigación y Género. Sevilla: Universidad de Sevilla, pp. 1.077-1.088 $<$ https://idus.us.es/xmlui/handle/11441/40560> [Consulta: 15/04/2019].

Vogeley, Nancy J. y Manuel Ramos Medina (2011). Historia de la literatura mexicana 3. Cambios de reglas, mentalidades y recursos retóricos en la Nueva España del siglo XVIII. Ciudad de México: Siglo xxi/Universidad Nacional Autónoma de México.

Recibido: 09/05/2019

Aceptado: 26/06/2019 
CRÍTICA Y ¿DEFENSA? DE LAS MUJERES EN UN «SERMÓN» SATíRICO NOVOHISPANO PROHIBIDO POR LA INQUISICIÓN (1795)

RESUMEN: El artículo analiza el discurso misógino y los recursos satíricos del Sermón contra las mujeres que circuló manuscrito hacia finales del siglo XVIII, el cual fue denunciado ante la Inquisición de México en 1795, así como los argumentos con los que los teólogos designados por los inquisidores como calificadores decidieron sugerir su prohibición. El objetivo consiste en determinar si el discurso de la Iglesia, representado en este caso por la opinión de los calificadores e inquisidores, propone argumentos en defensa de las mujeres y, en su caso, cuáles y de qué tipo son.

PALABRAS ClAVES: sátira novohispana, discurso misógino, sermón satírico.

\section{CRITICISM and Women's ¿DEFENSE? In a SATYRICAL NOVOHISPAN «SERMON» PROHIBITED BY THE INQUISITION (1795)}

ABSTRACT: The article analyzes the satirical resources and the misogynistic discourse of the Sermon against women which circulated manuscript by the end of the $18^{\text {th }}$ century and was denounced to the Inquisition of Mexico in 1795, as well as the arguments that the theologians designated by the Inquisitors as qualifiers took into count to suggest their prohibition. The objective of this essay is to determine if the discourse of the Church, represented in this case by the opinion of the qualifiers and inquisitors, proposed arguments in defense of women and, in such case, which and of what kind are they?

KEYWORDS: novohispanic satire, misogynist discourse, satirical sermon. 